\title{
Dirofilariasis: A Report on Emerging Zoonosis in South India
}

\author{
Anice Joy ${ }^{1}$, Narayanan $\mathrm{M}^{1}$, Ravi TV ${ }^{1}$, Binu PS ${ }^{2}$ \\ ${ }^{1}$ Department of Pediatrics and Neonatology, Ernakulam Medical Centre, Kochi, Kerala; ${ }^{2}$ Department of Pediatric Surgery, Ernakulam \\ Medical Centre, Kochi, Kerala, India.
}

\author{
Corresponding Author: \\ Dr. Anice Joy \\ Email: dr_anicejoy@gmail.com \\ This is an Open Access article distributed \\ under the terms of the Creative Commons \\ Attribution License (creativecommons.org/ \\ licenses/by/3.0). \\ Received : January 18, 2017 \\ Accepted : June 20, 2017 \\ Published : September 10,2017
}

\begin{abstract}
Background: Dirofilaria is a filarial nematode worm transmitted by mosquitoes which rarely causes human infection. Case Report: A twelve year old girl who was otherwise asymptomatic, presented with a small swelling of around $1 \mathrm{~cm}$ diameter over the anterior chest wall. Ultrasonography showed a small cystic swelling with a linear echogenic structure in persistent twirling motion suggestive of a live worm. She underwent surgical removal of the swelling which showed two live Dirofilaria repens. Conclusion: Dirofilariasis should be considered as an emerging zoonosis of Kerala. Mosquito control is the best preventive strategy.
\end{abstract}

Keywords: Animals, Dirofilaria reopens, Dirofilariasis, Humans, Mosquito Control.

\section{Introduction}

Human subcutaneous dirofilariasis is a zoonotic filarial infection caused by a filarial nematode worm belonging to genus dirofilaria, which principally affects several domestic and wild animals. The larval forms are transmitted to humans by mosquitoes. Humans are dead-end hosts and illness usually manifests as subcutaneous swelling, ocular or pulmonary involvement. We report a case of dirofilariasis in a 12 year old child, presenting as subcutaneous nodule in lower chest wall.

\section{Case Report}

A twelve year old girl from central Kerala presented with small swelling on lower anterior chest wall of three week duration. She otherwise had no systemic complaints. On examination there was a small tender swelling of around $1 \mathrm{~cm}$ diameter over the breast bone. Clinical examination was otherwise normal. There were no such swelling elsewhere or any lymphadenopathy. Blood investigations were also normal. There was no evidence of peripheral eosinophilia. The child was subjected to ultrasonographic examination which revealed a small cystic swelling of $1 \times 1 \mathrm{~cm}$ with a linear echogenic structure in persistent twirling motion suggestive of a live worm. Later the swelling was surgically removed and worm was removed alive. There were two live thin worms $1 \mathrm{~mm}$ in breadth with one $8 \mathrm{~cm}$ in length, other one $4 \mathrm{~cm}$ in length [Fig.1]. Worms were examined by the microbiologist who confirmed it as Dirofilaria and belonged to the species $D$. repens.

\section{Discussion}

Human Dirofilariasis is rare filarial zoonosis that reaches humans by bite of mosquitoes of Anopheles, Aedes and Culex species which are intermediate hosts that transmit microfilariae upon feeding on its principle reservoir host such as dogs, cats, foxes and several other wild animals. The maturation of infective larvae into adult form takes place inside dog's heart so it is also known by name "dog heartworm". Humans are hence, accidental dead-end hosts and cannot transmit infection from person-to-person. Human illnesses usually manifest as subcutaneous skin swelling (human subcutaneous dirofilariasis, 
HSD) or rarely, pulmonary dirofilariasis (human pulmonary dirofilariasis, HPD). The increase in the human dirofilarial infections are believed to be due to increase in mosquito density, warm climate that predisposes to extended mosquito breeding, increased human outdoor activities, close contact with dogs at home and abundance of microfilaraemia in stray dogs $[1,2]$.

The first documented case report of human Dirofilariasis was by Addario from Milan, Italy in 1885 and was described as an infection by filarial conjunctivae [3]. In Asian sub-continent, Srilanka is considered as the most endemic zone of dirofilariasis [4]. It may be due to this fact that south India, especially the state of Kerala harbours a focus of the dirofilariasis [5]. The climatic condition that prevails in the state also makes it an ideal condition for the vector to propagate. Apart from south Indian states, there have been reports of human dirofilariasis from Assam [5], Orissa [6], Meghalaya [7] and Mumbai [8]. The Dirofilaria species varies between various geographical regions. In India, the reported cases are mostly caused by $D$. repens, however there are reports of cases caused by D. immitis and D. tenuis [9]. $D$. repens usually manifest as subcutaneous migratory swellings which have a predilection for upper body sites because of mosquito biting over exposed areas. In the largest series reported on human subcutaneous dirofilariasis from Kerala, site of lesion involved was face or anterior chest wall [10]. Our patient also had similar presentation.

Simple extraction or surgical excision of the swelling is both diagnostic as well as therapeutic strategy of choice of human dirofilariasis. Anthelminthic chemotherapy is not required usually as there is no microfilaraemia reported in human dirofilariasis caused by $D$. repens.

\section{Conclusion}

The dirofilariasis should be considered as an emerging zoonosis in southern India. Clinicians

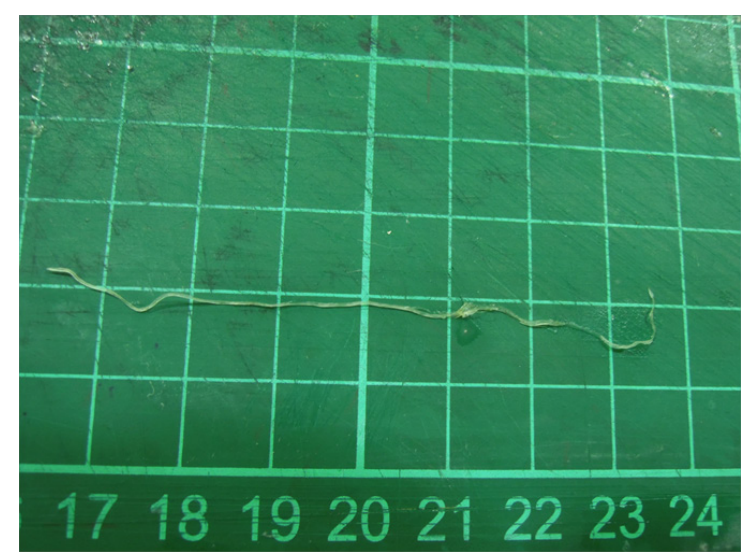

Fig.1: Two live thin worms $1 \mathrm{~mm}$ in breadth with $8 \mathrm{~cm}$ and $4 \mathrm{~cm}$ in length respectively, removed intact from the cystic swelling.

should always consider subcutaneous dirofilariasis in the differential diagnosis of subcutaneous nodules. Simple extraction or surgical excision of the swelling is both diagnostic as well as therapeutic strategy of human dirofilariasis. The control of abundance of domestic and stray dogs and the ubiquitous mosquito population are the most relevant preventive strategies.

Contributors: AJ: manuscript writing, literature search; NM: manuscript editing, diagnosis, patient management; RTV: manuscript editing, literature search; BPS: surgery and critical inputs into the manuscript. AJ will act as guarantor. All authors approved the final version of the manuscript.

Funding: None; Competing interests: None stated.

\section{References}

1. Simon F, Morchon R, Gonzalez-Miguel J, MarcosAtxutegi C, Siles-Lucas M. What is new about animal and human dirofilariosis? Trends Parasitol. 2009;25:404409.

2. Permi HS, Veena S, Kishan Prasad HL, Kumar YS, Mohan R, Shetty KJ. Subcutaneous human dirofilariasis due to Dirofilaria repens: Report of two cases. J Glob Infect Dis. 2011;3:199-201.

3. Addario C. Su un nematode dell'occhio umano. Ann Ottalmol. 1885;13:135-137.

4. Joseph A, Thomas PG, Subramaniam KS. Conjunctivitis by Dirofilaria conjunctivae. Indian $\mathrm{J}$ Ophthalmol. 1977;24:20-22.

5. Nath R, Gogoi R, Bordoloi N, Gogoi T. Ocular dirofilariasis. Indian J Pathol Microbiol. 2010;53:157159. 
6. Singh R, Shwetha JV, Samantaray JC, Bando G. Dirofilariasis: A rare case report. Indian J Med Microbiol. 2010;28:75-77.

7. Banik A, Khyriem AB, Lyngdoh WV, Lynrah KG. Subcutaneous dirofilariasis. Indian J Med Microbiol. 2013;31:403-405.

8. Sahdev SI, Sureka SP, Sathe PA, Agashe R. Ocular dirofilariasis: Still in the dark in western India? J Postgrad Med. 2012;58:227-228.

9. Badhe BP, Sane SY. Human pulmonary dirofilariasis in India: A case report. J Trop Med Hyg. 1989;92:425-426.

10. Joseph E, Matthai A, Abraham LK, Thomas S. Subcutaneous human dirofilariasis. J Parasit Dis. 2011;35:140-143. 